\title{
A METHOD FOR OBJECTIVE EVALUATION OF THE FERTILIZING ABILITY OF SPERMATOZOA IRRESPECTIVE OF GENETIC CHARACTER
}

\author{
J. M. BEDFORD* AND J. W. OVERSTREET \\ Department of Anatomy and International Institute for the Study of \\ Human Reproduction, Columbia University, \\ College of Physicians and Surgeons, New York, N.Y. 10032, U.S.A.
}

(Received 18th November 1971, accepted 21st February 1972)

\begin{abstract}
Summary. X-irradiation with 6000 to $10,000 \mathrm{rad}$ can be used as a method of 'marking' a population of rabbit spermatozoa without affecting their fertilizing ability. Following a mixed insemination, irradiated spermatozoa compete equally well with non-irradiated spermatozoa from the same population, as judged by differential egg development $50 \mathrm{hr}$ after insemination, at which time eggs fertilized by irradiated spermatozoa display obviously retarded cleavage.

In this paper, the technique has been used to demonstrate: (a) a subtle decrease in the fertility of spermatozoa after incubation in vitro at $40^{\circ}$ $\mathrm{C}$, which was not detectable by insemination of the treated sample alone, (b) the ability of spermatozoa from the proximal cauda epididymidis to initiate contact with and fertilize ova as readily as ejaculated spermatozoa following mixed insemination, there being no delay in the time of egg penetration by the epididymal spermatozoa, (c) the existence of selective fertilization between individuals of the same breed, as well as those differing genetically.

The irradiation marking technique could have many applications in comparative assessment of the fertility of semen from different individuals, irrespective of their genetic make-up, and in testing the effect of various treatments or environments on the fertilizing capacity of spermatozoa.
\end{abstract}

\section{INTRODUCTION}

By insemination of mixed ejaculates (heterospermic insemination), it is possible to compare the fertilizing ability of two populations of spermatozoa on the basis of their competitive performance within the same female tract. Such a system has value as a means for the objective evaluation of semen fertility, and a number of studies have been undertaken utilizing heterospermic insemination. These include investigations of selective fertilization, i.e. the superior fertility

* Present address: Cornell University Medical College, York Avenue and East 68th Street, New York 10021, U.S.A. 
of equivalent numbers of spermatozoa in semen from one male over the same number from another normally fertile male (Edwards, 1955; Beatty, 1957, 1960; Beatty, Bennett, Hall, Hancock \& Stewart, 1969; Overstreet \& Adams, 1971,1972 ) and the effects of various manipulations in vivo and in vitro on the fertility of the sperm sample (Roche, Dziuk \& Lodge, 1968; Miller, Roche \& Dziuk, 1969; Dziuk, 1970).

The method of approach in these investigations has three noteworthy limitations. Firstly, it is necessary that the semen to be compared should differ genetically in some easily detectable way since the results are based on identification in the offspring of paternal characters in the visual phenotype, or, alternatively, in their blood groups (Saison \& Moxley, 1966). Secondly, it is necessary to wait at least for the greater part of the gestation period before results can be obtained. Finally, where some variable other than the superiority of the fertility of one particular male compared to that of another is being studied, care must be taken to ensure that the individuals contributing the genetically marked spermatozoa do not themselves show fertility superiority to one another.

The purpose of the present paper is to draw attention to the feasibility of 'marking' the nucleus of spermatozoa by X-irradiation, without affecting fertilizing ability. In a previous study, Bedford \& Hunter (1968) have reported that X-irradiation of rabbit spermatozoa at a dose level up to 10,000 rad has no effect on their fertilizing ability. Thus, when aliquots of spermatozoa irradiated at 10,000 rad were inseminated together with comparable aliquots of normal spermatozoa from the same ejaculate, the irradiated spermatozoa fertilized $50 \%$ of the ova. In this system, identification of the fertilizing spermatozoon is simple, since, at $50 \mathrm{hr}$ after insemination and an ovulating injection, rabbit eggs fertilized by normal spermatozoa have generally developed to the sixteen-cell stage or further (Gregory, 1930), whereas eggs penetrated by irradiated spermatozoa (6000 to $10,000 \mathrm{rad}$ ) are activated but do not usually develop beyond the two- to three-cell stage, and never beyond four cells. The marking of spermatozoa by irradiation thus allows comparison of the fertilizing ability of sperm samples of any genetic type, or of aliquots of the same sample after differential treatment, the results of which can be obtained in $50 \mathrm{hr}$. Examples of the use of this technique in various experimental situations are outlined below.

\section{EXPLANATION OF PLATE 1}

Frg. 1. Four fresh ova recovered from a rabbit $50 \mathrm{hr}$ after injection of HCG and insemination of a mixture of X-irradiated and normal spermatozoa. An egg fertilized by a normal spermatozoon (upper left) can be distinguished easily by the fact that it has continued to divide, whereas the other three which have been fertilized by irradiated spermatozoa, are retarded and have only three cells. All of these eggs displayed several perivitelline spermatozoa. Phase contrast. $\times 335$.

FIGS 2 and 3. Both pictures show fixed and stained eggs recovered from a rabbit $50 \mathrm{hr}$ after the insemination of a mixture of irradiated and normal spermatozoa. The egg in Fig. 2 , fertilized by a normal spermatozoon, displayed sixteen blastomeres, each typically having an intact nucleus (N) or organized mitotic chromosomes. By contrast, the egg in Fig. 3, fertilized by an irradiated spermatozoon, is retarded at the two-cell stage and displays an eccentric group of chromosomes (C) in the upper blastomere and dispersed chromatin (G) in the lower. Acetic alcohol and lacmoid. Phase contrast. $\times 420$. 


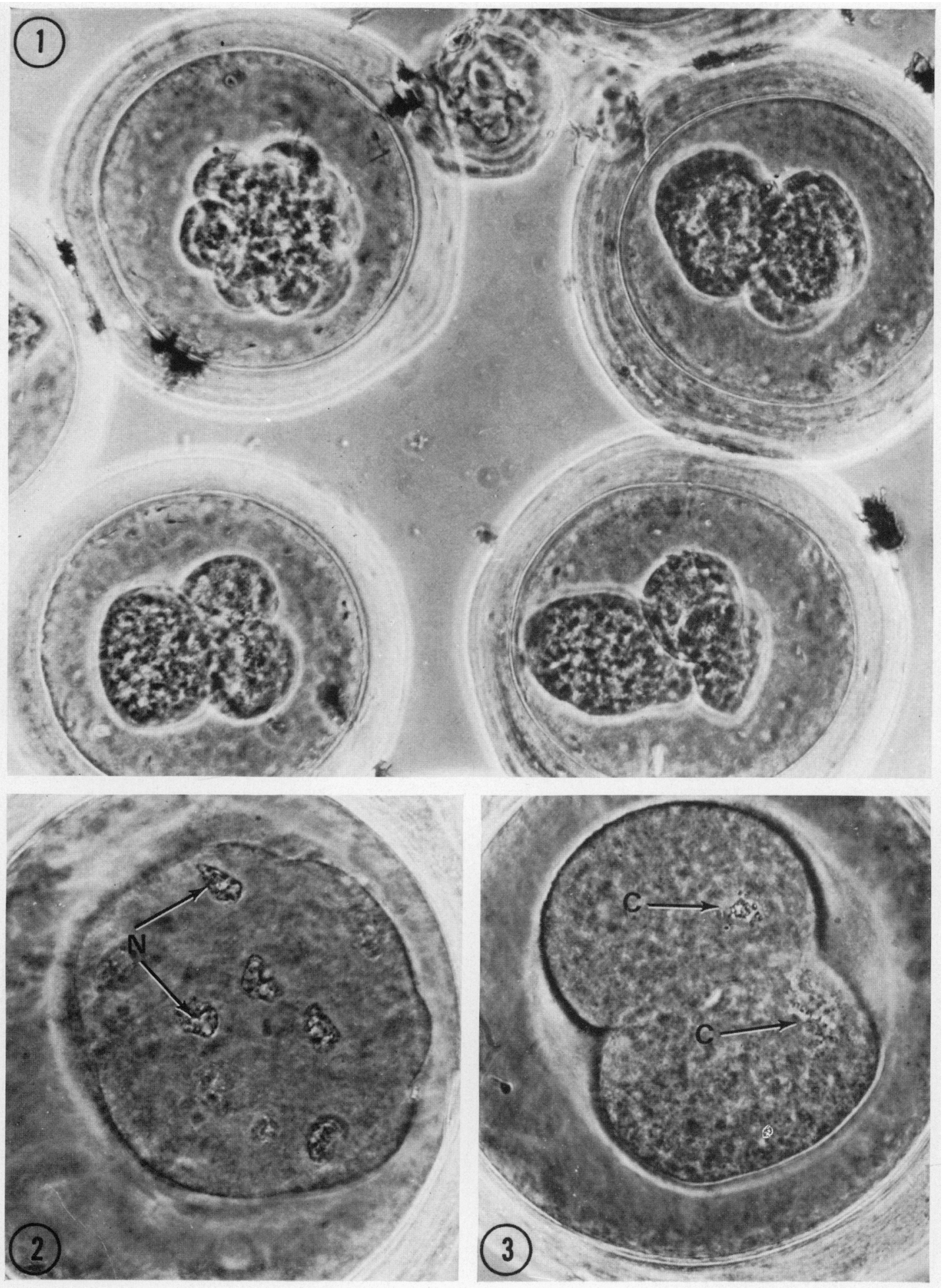

ifacing p. +108 


\section{MATERIALS AND METHODS}

Ejaculated spermatozoa were obtained from fertile male rabbits by collection into an artificial vagina. In experiments designed to compare ejaculated spermatozoa with those from the lower corpus and proximal cauda of the epididymis, the epididymal tissue was minced with iridectomy scissors directly into acidic saline (Hammond, 1949) with $5 \%$ heated rabbit serum and $0.25 \%$ glucose. In one series of experiments designed to study the effect of incubation at a slightly elevated temperature on the fertility of spermatozoa (Ulberg \& Burfening, 1967), an ejaculate sample was incubated at $40^{\circ} \mathrm{C}$ for $3 \mathrm{hr}$, a control aliquot of the sample being incubated likewise at $38^{\circ} \mathrm{C}$. The control or the experimental sample was then subjected to X-irradiation at a rate of $500 \mathrm{rad} /$ min, as described by Bedford \& Hunter (1968), a total dose of 6000 to 7000 rad being given. The two equal volumes containing motile irradiated or nonirradiated spermatozoa in equal numbers were mixed thoroughly, and the mixture was inseminated intravaginally into an oestrous rabbit which also received an ovulating injection of 100 i.u. HCG (Pregnyl-Organon).

For studies on selective fertilization, semen samples were collected from normally fertile Albino males (A4 and A8) and one Dutch Belted male (D1), and aliquots were irradiated as described above. In each experimental trial, irradiated and non-treated aliquots containing equal numbers of spermatozoa from each of two males were mixed, the respective mixtures being inseminated into two or more females. Thus, each inseminated sample contained equal numbers of ejaculated spermatozoa from each of the two bucks, one population of which had been irradiated. The source of the fertilizing spermatozoon, and thus the relative dominance of either male, was judged according to the development of eggs collected at $50 \mathrm{hr}$ and the identity of the irradiated sample.

Ova were collected from the inseminated females about $50 \mathrm{hr}$ after insemination and injection of HCG, at which time most ova fertilized by normal spermatozoa would have reached the sixteen-cell stage. The ova were assessed by phase microscopy for the stage of cleavage, for perivitelline spermatozoa, and for the stage of the nuclei or mitotic figures in the blastomeres, as described elsewhere (Bedford \& Hunter, 1968). In the eggs which had only reached the two- to four-cell stage with or without fragmentation, the presence of one or more perivitelline spermatozoa was taken as evidence of fertilization when the fertilizing sperm tail could not be found.

Though not likely, it nevertheless seemed possible that the results presented here might have been biased if, in the stock of rabbits used, a significant proportion of eggs fertilized by non-irradiated spermatozoa had failed to develop normally to the sixteen-cell stage. For this reason, we also studied the stage of development of eggs collected at 48 to $50 \mathrm{hr}$ from females mated with normal males.

\section{RESULTS}

Effect of 6000 to 7000 rad on the fertilizing ability of rabbit spermatozoa

In confirmation of an earlier study (Bedford \& Hunter, 1968), the present 
results show that irradiation with 6000 to $7000 \mathrm{rad}$ at a dose of $500 \mathrm{rad} / \mathrm{min}$ does not affect the fertilizing ability of rabbit spermatozoa. For, when equal numbers of irradiated and normal spermatozoa from the same ejaculate were inseminated in a mixed suspension into ten females, a total of forty-one penetrated eggs recovered $50 \mathrm{hr}$ later were at the four-cell stage or less, forty-one eggs had reached the sixteen-cell stage, and two eggs were unfertilized (Table 1).

In these and subsequent experiments, there is little doubt that the eggs reaching four cells or less at $50 \mathrm{hr}$ had been fertilized by irradiated spermatozoa. Seventy-seven out of seventy-eight $(98.5 \%)$ of the eggs of seven control females, killed $50 \mathrm{hr}$ after mating with one or more normal males, had developed to the sixteen-cell stage; an indication that the 'normal' proportion of eggs at the four-cell stage or less which are fertilized by non-irradiated spermatozoa is negligible.

TABLE 1

EGG DEVELOPMENT 50 HR AFTER MIXED INSEMINATION OF EQUIVALENT NORMAL AND IRRADIATED ALIQUOTS FROM A SINGLE RABBIT SEMEN SAMPLE

\begin{tabular}{c|c|c|c|c}
\hline Male no. & $\begin{array}{c}\text { No. of eggs } \\
\text { recovered }\end{array}$ & $\begin{array}{c}\text { No. of eggs } \\
\text { at 16-cell } \\
\text { stage }\end{array}$ & $\begin{array}{c}\text { No. of eggs } \\
\text { at 4-cell } \\
\text { stage or less }\end{array}$ & $\begin{array}{c}\text { No. of eggs } \\
\text { unfertilized }\end{array}$ \\
\hline 281 & 5 & 3 & 2 & - \\
298 & 10 & 3 & 7 & - \\
302 & 7 & 4 & 3 & - \\
299 & 9 & 4 & 4 & - \\
297 & 9 & 4 & 5 & - \\
303 & 10 & 5 & 5 & - \\
300 & 11 & 3 & 2 & 1 \\
301 & 5 & 3 & 2 & 2 \\
305 & 5 & 8 & 4 & - \\
294 & 13 & 41 & 41 & - \\
Total & 84 & 3 & & \\
\hline
\end{tabular}

Aliquots irradiated at 7000 rad.

Effect of heating spermatozoa at $40^{\circ} \mathrm{C}$

Ulbert \& Burfening (1967) concluded that heating of rabbit spermatozoa to $40^{\circ} \mathrm{C}$ for $3 \mathrm{hr}$ had no effect on fertilizing ability since, on insemination, they were able to fertilize $98 \%$ of eggs. By contrast, our mixed insemination experiments with sperm samples incubated at 40 and $38^{\circ} \mathrm{C}$ provide evidence of a subtle depression of the fertility of spermatozoa incubated at the higher temperature since, in fourteen trials, these spermatozoa fertilized only 64 of 185 eggs $\left(34^{\circ} \%\right)$ in direct competition with an equal number of control $\left(38^{\circ} \mathrm{C}\right)$ spermatozoa which fertilized 111 eggs $(60 \%)$. Moreover, spermatozoa in the control samples fertilized more than $50 \%$ of the eggs in twelve of fourteen trials (Table 2). It is clear, therefore, that, although incubation of ejaculated spermatozoa at $40^{\circ} \mathrm{C}$ does not prevent normal levels of fertilization when the treated samples are inseminated alone (Table 2), a detrimental effect on fertility is revealed when they are placed in direct competition with spermatozoa incubated at $38^{\circ} \mathrm{C}$. 
Comparison of the fertilizing ability of ejaculated and mature epididymal spermatozoa

Many rabbit spermatozoa first became competent to fertilize in the lower corpus region of the epididymis (Bedford, 1966; Orgebin-Crist, 1967). However, careful study of the succeeding stages leading to syngamy and cleavage has indicated that eggs fertilized by spermatozoa from the corpus or cauda epididymidis show a somewhat retarded rate of early development compared with those fertilized by ejaculated spermatozoa (Orgebin-Crist, 1967, 1968; Overstreet, 1970). This difference could result from delay in penetration, extension of the time needed for pronucleus formation and syngamy, and/or retardation of the rate of early embryonic cell division.

We have tested the first of these possibilities in thirteen males by mixed

TABLE 2

EFFECT OF AN ELEVATED TEMPERATURE ( $40^{\circ}$ C FOR 3 HR) ON THE FERTILITY OF RABBIT SPERMATOZOA, AS JUDGED BY THEIR ABILITY TO COMPETE WITH CONTROL $\left(38^{\circ} \mathrm{C}\right)$ SPERMATOZOA FOLLOWING MIXED INSEMINATION

\begin{tabular}{|c|c|c|c|c|c|c|}
\hline \multirow{2}{*}{$\begin{array}{l}\text { Experiment } \\
\text { no. }\end{array}$} & \multicolumn{2}{|c|}{$\begin{array}{l}\text { No. of females } \\
\text { inseminated }\end{array}$} & \multicolumn{2}{|c|}{$\begin{array}{l}\text { No. of eggs } \\
\text { recovered }\end{array}$} & \multicolumn{2}{|c|}{$\begin{array}{c}\text { No. of eggs fertilized } \\
\text { by } 40^{\circ} \mathrm{C} \text {-treated } \\
\text { spermatozoa }\end{array}$} \\
\hline & $\begin{array}{c}\text { Mixed } \\
\left(40^{\circ} C+38^{\circ} C\right)\end{array}$ & $\begin{array}{c}40^{\circ} C \text { only } \\
(\text { control })\end{array}$ & $\begin{array}{c}\text { Mixed } \\
\left(40^{\circ} C+38^{\circ} C\right)\end{array}$ & $\begin{array}{l}40^{\circ} C \\
\text { only }\end{array}$ & Mixed & $\begin{array}{c}40^{\circ} \mathrm{C} \\
\text { only }\end{array}$ \\
\hline $\begin{array}{r}1 \\
2 \\
3 \\
4 \\
5 \\
6 \\
7 \\
8 \\
9 \\
10 \\
11 \\
12 \\
13 \\
14\end{array}$ & $\begin{array}{l}2 \\
2 \\
1 \\
1 \\
2 \\
1 \\
1 \\
1 \\
1 \\
2 \\
2 \\
2 \\
2 \\
2\end{array}$ & $\begin{array}{l}1 \\
1 \\
1 \\
1 \\
1 \\
1 \\
1 \\
1 \\
1 \\
1 \\
1 \\
2 \\
2 \\
2\end{array}$ & $\begin{array}{r}10 \\
13 \\
2 \\
7 \\
15 \\
13 \\
10 \\
8 \\
7 \\
22 \\
16 \\
16^{*} \\
26 \\
22\end{array}$ & $\begin{array}{r}19 \\
10 \\
11 \\
8 \\
10 \\
7 \\
7 \\
8 \\
13 \\
15 \\
20 \\
21\end{array}$ & $\begin{array}{r}2 \\
9 \\
0 \\
0 \\
5 \\
3 \\
4 \\
2 \\
1 \\
13 \\
6 \\
4 \\
9 \\
6\end{array}$ & $\begin{array}{r}19 \\
10 \\
4 \\
1 \\
10 \\
7 \\
7 \\
7 \\
11 \\
9 \\
17 \\
18\end{array}$ \\
\hline Total & 22 & 17 & 187 & 149 & $64(34 \%)$ & $120(80 \%)$ \\
\hline
\end{tabular}

* Five eggs unfertilized.

insemination of balanced numbers of epididymal and ejaculated spermatozoa taken from the same male, one of the samples being marked by irradiation with $7000 \mathrm{rad}$. In all, a total of thirty-seven females were inseminated in this way at the time of administration of an ovulating injection of HCG. The results, which will be reported in more detail elsewhere, show that ejaculated spermatozoa inseminated at the time of the HCG injection hold no advantage over epididymal spermatozoa in the same inseminate, in their ability to 'win' the egg. For, as judged from the developmental stage of eggs following the radiation marking of either sperm sample, $52 \%$ of 251 eggs fertilized were penetrated by ejaculate spermatozoa and $48 \%$ by epididymal spermatozoa.

\section{Selective fertilization among fertile males}

Appropriate examples of the use of irradiation marking in the study of 
selective fertilization are outlined below. These results are presented in detail elsewhere in conjunction with other data (Overstreet \& Adams, 1971).

When irradiation marking was used to compare the semen from two bucks, $\mathrm{A} 4$ and $\mathrm{DI}, 85 \%$ of ninety-nine zygotes recovered from eight females were fertilized by spermatozoa from D1. This superiority was maintained when intratubal insemination was performed with mixtures of 10 to $20 \times 10^{4}$ spermatozoa, $85 \%$ of fifty-six zygotes from eleven females being fertilized by D1. The validity of this conclusion that D1 was clearly superior to A4, was confirmed by control experiments in which identification of the fertilizing spermatozoon was based on the colour marking of the fetuses at term. In this case, $92 \%$ of 140 fetuses from nineteen females inseminated per vaginam had coat colouring expressive of the paternity of the Dutch Belted spermatozoa.

Irradiation marking of spermatozoa has also been used to demonstrate that selective fertilization operates between rabbits of the same strain. Although Albino males A4 and A8 were both normally fertile, mixed insemination showed that A4 also competed unfavourably with A8 following irradiation of the semen of either male; for, as judged by their development at $50 \mathrm{hr}$ after insemination, $77 \%$ of 113 zygotes from eight females were fertilized by spermatozoa from A8.

\section{DISGUSSION}

While obviously inappropriate for assessment of the potential of the sperm genome for normal embryonic development, X-irradiation of rabbit spermatozoa at about 7000 rad permits determination of the identity of the fertilizing spermatozoon, in competitive situations, as early as $50 \mathrm{hr}$ after mixed insemination. This method of marking spermatozoa without affecting fertilizing ability (Table 1) seems particularly suitable for detecting subtle differences in the functional quality of sperm samples which would not become apparent in tests involving separate insemination into different females (Table 2). The method is similarly appropriate where genetic markers are absent, when attempting to compare the relative fertilizing ability of semen from siblings, or from males of different generation within the same line. Moreover, the irradiation marking technique seems ideal for comparison of sperm storage methods where aliquots of spermatozoa from the same original population can subsequently be tested against each other after exposure to the conditions under investigation. A negligible proportion of eggs were retarded at the four-cell stage or less $50 \mathrm{hr}$ after fertilization by untreated spermatozoa from stud males in these experiments. However, it would seem advisable to check males of unknown fertility in this way before their inclusion in prolonged studies involving comparison of different males. As in the examples used here, any treatment being assessed should not seriously affect the capacity of the spermatozoa to support normal development of the zygote, up to the sixteen-cell stage at least.

Irradiation marking will almost certainly prove useful for studies which involve comparison of the capacitation potential either of different organs, or of one organ, e.g. the uterus, in various endocrine conditions. Studies of this type have already been reported using staggered double insemination (Dziuk, 
1965), but it should be pointed out that in those and subsequent experiments (Roche et al., 1968; Miller et al., 1969; Dziuk, 1970; O'Reilly, Graves \& Dziuk, 1971), a number of males from the same breed were used as donors of genetically marked semen. The findings of Overstreet \& Adams (1971, 1972) show clearly that, in the rabbit at least, fertility superiority of fresh semen is largely an attribute of the individual male and is not solely a breed or strain characteristic. Therefore, critical interpretation of such results is made difficult without precise information on the competitive fertility performance of each individual male against all those males with which his semen was mixed. The use of the irradiation marking technique for this type of study would eliminate the unknown contribution of such variables to the results since, in using sperm samples from only one male, or aliquots of a semen pool, possible physiological differences between males are eliminated. Obviously, factors such as sperm transport may also complicate the interpretation of results in many experiments of this type. However, such variables can be evaluated by additional labelling of the irradiated or the control sample (the latter is preferable only from a logistical standpoint) with fluorescein isothiocyanate (Mellish \& Baker, 1970). This fluorescent label is retained on spermatozoa in the female tract, without depressing fertilizing capacity and a combination of the two methods allows a critical correlation and comparison of sperm survival, transport and fertilizing ability as well as relative numbers of supplementary spermatozoa around the egg (Overstreet \& Adams, 1971).

Though appropriate levels of irradiation must first be established for any one species, there is no obvious reason why this principle should not be employed in other animals. For instance, this might afford a means of objective evaluation of the effect on fertilizing ability of genetic selection for change in the proportions of the sperm head or mid-piece (Beatty, 1970; Woolley, 1970). In domestic species, it could provide a rapid means of evaluation of the relative fertilizing ability of semen from potential stud males.

\section{ACKNOWLEDGMENTS}

The data reported here were obtained with the support of N.I.H. grant HD 03623. The assistance of Mrs Mary-Jane Bent is gratefully acknowledged. One of us (J.W.O.) is supported by a Medical Scientist Training Fellowship (Grant GM 02042).

\section{REFERENCES}

BeAtty, R. A. (1957) A pilot experiment with heterospermic insemination in the rabbit. 7. Genet. 55, 315.

BeAtTy, R. A. (1960) Fertility of mixed semen from different rabbits. F. Reprod. Fert. 1, 52.

Beatty, R. A. (1970) The genetics of the mammalian gamete. Biol. Rev. 45, 73.

Beatty, R. A., Bennett, J. H., Hall, J. G., Hancock, J. L. \& Stewart, D. L. (1969) An experiment with heterospermic insemination in cattle. F. Reprod. Fert. 19, 491.

BEDFoRd, J. M. (1966) Development of fertilizing ability of spermatozoa in the epididymis of the rabbit. 7. exp. Zool. 163, 319 .

BedFoRd, J. M. \& HuNTER, R. H. F. (1968) The influence of X-irradiation of rabbit spermatozoa on fertilization and early cleavage. F. Reprod. Fert. 17, 49.

Dzruk, P. J. (1965) Double mating of rabbits to determine capacitation time. 7. Reprod. Fert. 10, 389. 
Dzruk, P. (1970) Estimation of optimum time for insemination of gilts and ewes by double mating at certain times relative to ovulation. F. Reprod. Fert. 22, 277.

EDWARDs, R. G. (1955) Selective fertilization following the use of sperm mixtures in the mouse. Nature, Lond. 175, 215.

Gregory, P. W. (1930) The early embryology of the rabbit. Contr. Embryol. 21, 141.

Hammond, J., JR (1949) Recovery and culture of tubal mouse ova. Nature, Lond. 163, 28.

MeLuish, K. S. \& BAKER, R. D. (1970) Marking boar spermatozoa with fluorochromes for evaluating spermatozoan transport within gilts. F. Anim. Sci. 31, 917.

Mruler, O. G., Roche, J. F. \& Dzruk, P. J. (1969) Estimation of the optimum interval between insemination and ovulation in the rabbit by double insemination. F. Reprod. Fert. 19, 545.

O'Reilly, P. J., Graves, G. N. \& Dziuk, P. J. (1971) Heterospermic insemination of rabbit semen as a means of evaluating techniques of semen handling. F. Reprod. Fert. 29, 49.

ORGEBIN-CRIST, M. C. (1967) Maturation of spermatozoa in the rabbit epididymis: fertilizing ability and embryonic mortality in does inseminated with epididymal spermatozoa. Annls Biol. anim. Biochim. Biophys. 7, 373.

ORGEBIN-CRIST, M. G. (1968) Maturation of spermatozoa in the rabbit epididymis : delayed fertilization in does inseminated with epididymal spermatozoa. F. Reprod. Fert. 16, 29.

Overstreet, J. W. (1970) Fertilizing capacity of epididymal spermatozoa. F. Reprod. Fert. 21, 423.

Overstreet, J. W. \& Adams, C. E. (1971) Mechanisms of selective fertilization in the rabbit: sperm transport and viability. F. Reprod. Fert. 26, 219.

Overstreet, J. W. \& Adams, C. E. (1972) Mechanisms of selective fertilization in the rabbit. II. Sperm capacitation. Biol. Reprod. (in press).

Roche, J. F., DzIUK, P. J. \& LODGE, J. R. (1968) Competition between fresh and aged spermatozoa in fertilizing rabbit eggs. 7. Reprod. Fert. 16, 155.

SAIson, R. \& MoxLEY, J. E. (1966) The use of blood groups as markers in a double mating program in swine and evidence for preferential fertilization. $X^{e}$ Congrès Européen sur les Groupes Sanguins et le Polymorphisme Biochimique des Animaux. Paris.

UlBerG, L. G. \& BURfening, P. T. (1967) Embryo death resulting from adverse environment on spermatozoa or ova. F. Anim. Sci. 26, 571.

Woolley, D. M. (1970) A test of the functional significance of the quantity of mitochondria in the spermatozoa of mice. Genet. Res. 16, 225. 